\title{
FOOD QUALITY COMPETITION AMONG COMPANIES AND GOVERNMENT FOOD SAFETY SUPERVISION UNDER ASYMMETRIC PRODUCT SUBSTITUTION
}

\author{
Ningzhou Shen ${ }^{1 *}$, Yinghua Song ${ }^{2}$, Dan Liu ${ }^{3}$ and Dalia Streimikiene ${ }^{4}$ \\ ${ }^{1223)}$ China Research Center for Emergency Management, Wuhan University \\ of Technology and School of Safety Science and Emergency Management, \\ Wuhan University of Technology, Wuhan, China \\ 4) Lithuanian Institute of Agrarian Economics, Vilnius, Lithuania
}

Please cite this article as:

Shen, N., Song, Y., Liu, D. and Streimikiene, D., 2021.

Food Quality Competition Among Companies and Government Food Safety Supervision Under Asymmetric Product Substitution. Amfiteatru Economic, 23(56), pp. 221-239.

DOI: $10.24818 / \mathrm{EA} / 2021 / 56 / 221$
Article History

Received: 11 September

2020

Revised: 1 November 2020

Accepted: 25 November

2020

\begin{abstract}
The frequent exposures of food safety events in recent years have aroused extensive social concerns. Food quality and safety are hot topics in the food engineering field. In a market with mutual competitions, the products of different enterprises are substitutive, and enterprises have to achieve reasonable yield and to ensure product quality to maximize their profits. However, the limited production resources of enterprises affect their strategies in yield and quality. To explore enterprises' decisions in yield and food quality under no resource constraint as well as with yield and quality under resource constraints, a Cournot model with differential product substitution was constructed by using game theory, and the effects of government monitoring on food quality decision were further investigated. Results show that enterprises with strong product substitutability increase the yield and quality of their products. They can gain higher profits under no resource constraint and under resource constraint, but their profits are lower under quality constraint compared to the profits of enterprises with low product substitutability. When the equilibrium quality of enterprises is lower than the lowest quality standard requirements of the government, a high penalty $(\beta)$ or a relatively low government supervision difficulty $(\bar{c})$ urges enterprises to improve product quality. Under this circumstance, two enterprises produce according to the lowest quality standards. On the contrary, enterprises take certain risks to produce lowquality products to increase profits. The conclusions provide a theoretical basis to formulate food safety regulation policies from the perspective of product substitutability.
\end{abstract}

Keywords: food safety; Cournot competition; asymmetric product substitution; game theory

JEL Classification: I20, I23, O15, P46

*Corresponding author, Ningzhou Shen-e-mail: 141005@ whut.edu.cn

Vol. $23 \cdot$ No. $56 \cdot$ February 2021 


\section{Introduction}

The research field of food engineering is very extensive, involving microorganism, chemistry, technological process, public health, and risk assessment among other areas (Rodriguez-Parada, et al., 2018; Neumann-Langdon et al., 2019; Tomerlin et al., 2019; Aray et al., 2020; Datta et al., 2020). Food safety problems have attracted the extensive attention of the whole society. In particular, food quality and safety has become a very important research direction in the food engineering field (Petrovic et al., 2018; PinedaEscobar, 2019; Luo et al., 2020). Food safety scandals have been reported continuously in various media in recent years (Yan, 2012; Liu, Pieniak and Verbeke, 2013; Liu and Ma, 2016). For example, Burger King, the international fast food giant, was exposed for using expired ingredients in 2020. In 2008, Sanlu was exposed for adding melamine to its milk powder (Pei et al., 2011). In 2005, KFC, another international fast food giant, was exposed for the illegal use of food additives. Exposures of a series of food safety problems have not only greatly damaged consumers' trust in the food industry but also caused a crisis of public confidence over food safety. Therefore, food safety and quality in food engineering has become a problem that governments and consumers are concerned about more and more (Wang et al., 2008; Liu, 2010; Peng et al., 2015).

Factors that influence food safety mainly come from two aspects. On the one hand, consumers are concerned about price and food quality during food purchase, which forces competing enterprises in the market to gain advantages through quality control (Yang and Nie, 2016; Han and Li, 2017). On the other hand, governments supervise the product quality of enterprises in consideration of public safety in order to guarantee that the food quality meets specific standard (Song et al., 2018). However, previous studies demonstrate that the same type of products from different brands are substitutive to some extent (Besanko et al., 2005), and enterprises consider the substitutability of their competitors' products when making decisions regarding yield and quality of products (Shaffer and Zettelmeyer, 2004; Zheng et al., 2020). Enterprises in the market influence consumers' cognition of and preferences for products through advertisement and other means, resulting in different brand influences and substitutability of enterprise products (Shaffer and Zettelmeyer, 2004). As a result, the differences in product substitutability can directly influence enterprises' decision regarding yield and quality. However, existing studies neglect the differences among enterprises in product substitutability. The effects of differences in product substitutability among enterprises on their decision regarding product quality under double oligopolistic competition were analyzed on the basis of the Cournot competition model. Moreover, enterprise decision in production resources when there are yield and quality constraints was discussed. Accordingly, the effects of government supervision on the decision of enterprises were further analyzed.

The remainder of this study is organized as follows. Section 1 provides the literature review. Section 2 introduces the research methodology. Cournot competition models under no resource constraint and under yield and quality resource constraints were constructed, respectively. On this basis, the government-enterprise game model under government supervision was constructed. Section 3 introduces the analysis of results. The enterprise balances among yield, quality, and profits under three situations were analyzed. The yieldquality balance of enterprises under government supervision and equilibrium of government supervision input was also investigated. Section 4 provides the discussions. 
Management and policy enlightenments were disclosed according to the result analysis. The last section draws the main conclusions of this study.

\section{Literature review}

For food safety and quality in food engineering, foods should meet both yield and quality requirements to ensure consumers gain enough standard-quality foods (Pinstrup-Andersen, 2009; Yang and Nie, 2016). Many scholars are concerned about food safety problems in food engineering and have studied such concern from different perspectives. PinstrupAndersen (2009) discussed the definition and measurement standards of food safety. Tirado et al. (2010) reviewed the potential influences of climatic changes on food contamination and food safety as well as analyzed food safety and relevant strategies in different stages of the food supply chain. Liu and Ma (2016) constructed a hierarchical analysis model of cities in China to investigate food safety scandals, media exposure, and public safety concerns as well as disclose the influences of food safety scandals and media exposure on food safety risks.

The above studies mainly discussed food safety from the perspectives of the natural environment, government, and consumers but neglected the role of enterprises in food safety. Hence, some scholars focus on the food quality management of enterprises in the food supply chain (Rong et al., 2011; Chen et al., 2014; Migliore et al., 2015). Van Der Vorst et al. (2009) studied the increasing demands of consumers in the food supply chain for food quality and sustainability and proposed a new method to integrate logistics, sustainability, and food quality analysis. Wang et al. (2015) constructed the game models of enterprises under three cooperation situations to analyze the quality and safety inputs of enterprises and their effects on enterprise profits and food safety. Meanwhile, an evolutionary game model was built to investigate factors that influence the cooperation strategies of enterprises through theoretical and simulation analyses. Rouvière (2016) discussed the relationship between enterprise scale and preventive measures of enterprise food safety and found that small companies often made more efforts than do large companies. Parker et al. (2016) studied the food safety problems at farms and found that good agricultural practice knowledge has no significant differences among farms with different scales. Planters in small-scale production believe that food safety standards cannot adapt to local agricultural conditions and their agricultural scales. Chen et al. (2017) studied the impacts of enterprise social responsibility on food safety, and It is generally believed that positive price control and quality control lower the benefits of monopolists, consumer surplus, and social welfare (Nguyen et al., 2018; Hatami and Firoozi, 2019; Mauricio et al., 2019; Lu et al., 2020a, 2020b). Given incomplete information, monopolists may exaggerate product quality and enterprises may lower their exaggeration degree of quality due to quality control. Han and Li (2017) constructed a food safety evolutionary game model based on the improved prospect theory and found that food safety is difficult to utilize as an evolutionary stabilization strategy. Luo et al. (2018) constructed a game model among enterprises, consumers, and government supervision agencies as well as analyzed the effects of cost for food information searching, the subjective perception of consumers to foods, and the authentication effect of government supervision departments on food safety risks. Song et al. (2018) constructed an evolutionary game model of food safety information disclosure and analyzed the main influencing factors of information disclosure between government and enterprises. Xu et al. (2020) analyzed the quality decisions of 
subjects in the supply chain of agricultural products and discovered that a decentralization decision is more beneficial to improve the quality of agricultural products compared to a centralization decision.

However, these studies ignored product substitutability in the competition of enterprises (Vives, 2008; Yang and Nie, 2016). Chen et al. (2018) considered product substitutability among different enterprises when they were studying product quality decisions of enterprises in a Cournot competition. Unfortunately, they ignored product differences caused by factors such as the technological innovation of enterprises, further resulting in differences of product substitutability (Vives, 2008; Cunha and Mota, 2020). As a result, differences of product substitutability among different enterprises were taken into account and a Cournot model of double oligopolistic competition was built to analyze the yield and quality decisions of enterprises under no resource constraint and under yield and quality resource constraints. Moreover, a government-enterprise game model under government supervision was built to analyze the yield and quality decisions of enterprises under government supervision and government supervision input (Bojanić, 2015; Civera et al., 2019).

\section{Methodology}

\subsection{Cournot competition model under no resource constraint}

Given a double oligopolistic competition model under government supervision, there are two competing enterprises ( $i$ and $j$ ) on the market and they acquire the maximum benefits through a reasonable allocation of production capacity, that is, yield and quality of products. Since two enterprises produce the same types of products, the products are substitutable to some extent. The differences between two enterprises in product substitutability caused by technological factors are likewise taken into account. It is supposed that the enterprise with a stronger competitive edge has stronger product substitutability than its competitor. In this case, the product demand function (Chen and Nie, 2014; Nie, 2014; Chen et al., 2018) of enterprise $i$ can be expressed as

$$
P_{i}=\alpha+q_{i}-x_{i}-\gamma_{1} x_{j}
$$

where $\alpha$ refers to the market scale of products, $x_{i}$ is the yield of enterprise $i, q_{i}$ denotes the product quality of enterprise $i, x_{j}$ is the yield of enterprise $j$, and $\gamma_{1} \in[0,1]$ expresses product substitutability of enterprise $j$. Similarly, the product demand function of enterprise $j$ can be gained as

$$
P_{j}=\alpha+q_{j}-x_{j}-\gamma_{2} x_{i}
$$

where $q_{j}$ denotes the product quality of enterprise $j, \gamma_{2} \in[0,1]$ expresses product substitutability of enterprise $i$.Without loss of generality, we suppose that enterprise $i$ is more advantageous than enterprise $j$ and its product substitutability is stronger: $\gamma_{2}>\gamma_{1}$ and $\gamma_{1}, \gamma_{2} \in[0,1]$. 
On the double oligopolistic market, enterprises determine product quality in the first stage and determine product yield in the second stage. The revenue functions of enterprises $i$ and $j$ are

$$
\begin{array}{r}
\max _{x_{i}, q_{i}} \pi_{i}=\left(\alpha+q_{i}-x_{i}-\gamma_{1} x_{j}\right) x_{i}-\left(\frac{q_{i}^{2}}{2}+\frac{x_{i}^{2}}{2}+q_{i} x_{i}\right) \\
\max _{x_{j}, q_{j}} \pi_{j}=\left(\alpha+q_{j}-x_{j}-\gamma_{2} x_{i}\right) x_{j}-\left(\frac{q_{j}^{2}}{2}+\frac{x_{j}^{2}}{2}+q_{j} x_{j}\right)
\end{array}
$$

\subsection{Cournot competition model under yield resource constraint}

Under the yield capacity constraint, the production input resource constraint of the enterprise leads to the limited yield of product. The enterprise will further consider the influences of production input resource constraint on yield when it is making decisions regarding yield. At this moment, the model is

$$
\begin{gathered}
\max _{x_{i}, q_{i}} \pi_{i}=\left(\alpha+q_{i}-x_{i}-\gamma_{1} x_{j}\right) x_{i}-\left(\frac{q_{i}^{2}}{2}+\frac{x_{i}^{2}}{2}+q_{i} x_{i}\right) \\
\max _{x_{j}, q_{j}} \pi_{j}=\left(\alpha+q_{j}-x_{j}-\gamma_{2} x_{i}\right) x_{j}-\left(\frac{q_{j}^{2}}{2}+\frac{x_{j}^{2}}{2}+q_{j} x_{j}\right) \\
\text { S.T. } \theta\left(x_{i}+x_{j}\right) \leq R
\end{gathered}
$$

where $R$ is the resource constraint related to yield, and $\theta$ is the yield conversion efficiency of production resources. A high value of $\theta$ means low yield conversion efficiency of production resources, while a low value of $\theta$ means high yield conversion efficiency of production resources.

\subsection{Cournot competition model under quality resource constraint}

When there is a quality resource constraint, the production resource constraint can lead to the limited product quality of the enterprise. The enterprise will further consider the influences of resource constraint on quality when it is making a quality decision. In this case, the Cournot competition model is as follows:

$$
\begin{gathered}
\max _{x_{i}, q_{i}} \pi_{i}=\left(\alpha+q_{i}-x_{i}-\gamma_{1} x_{j}\right) x_{i}-\left(\frac{q_{i}^{2}}{2}+\frac{x_{i}^{2}}{2}+q_{i} x_{i}\right) \\
\max _{x_{j}, q_{j}} \pi_{j}=\left(\alpha+q_{j}-x_{j}-\gamma_{2} x_{i}\right) x_{j}-\left(\frac{q_{j}^{2}}{2}+\frac{x_{j}^{2}}{2}+q_{j} x_{j}\right) \\
\text { S.T. } \theta\left(q_{i}+q_{j}\right) \leq R
\end{gathered}
$$


Similarly, $R$ refers to quality-related resource constraint, and $\theta$ refers to the quality conversion efficiency of production resources. A high value of $\theta$ implies the low quality conversion efficiency of production resources, while a low value of $\theta$ indicates the high quality conversion efficiency of production resources.

\subsection{Modeling enterprise quality decision under government supervision and optimal government supervision input}

Yield and quality decisions of an enterprise under government quality supervision were further taken into account on the basis of the Cournot competition model. Moreover, product quality and yield of an enterprise are beyond the resource constraint. In this model, the government will input certain costs to supervise the product quality of enterprises. With the increase of supervision costs, the probability of the government detecting low-quality products increases accordingly. The government will confiscate all profits of the enterprise and impose a certain penalty for the discovered low-quality products. At this moment, the utility function of government is

$$
\pi_{G}=\delta(q) \stackrel{c}{=}(\pi+\beta)-\frac{c^{2}}{2}
$$

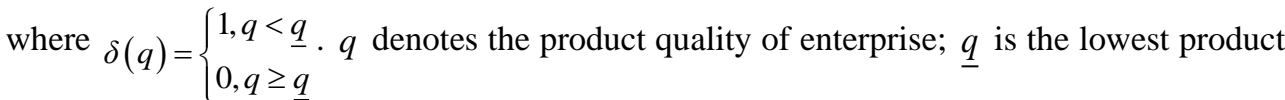
quality required by the government; $\pi$ is the profits of the enterprise; $c$ is the supervision input of the government; and $\bar{c}$ is the upper limit of government input, that is, the input needed for the government to discover product quality problems timely and accurately. When government input reaches the upper limit, the government will discover low-quality products timely at the probability of 1 and impose a penalty on the enterprise. A higher value of $\bar{c}$ reflects the bigger difficulties of government supervision. $\frac{c^{2}}{2}$ refers to the cost for such input, and $\beta$ refers to the government penalty on the enterprise. In this case, the utility function of enterprise $i$ is

$$
\begin{aligned}
& \pi_{i}=\left[1-\delta\left(q_{i}\right)\right]\left[\left(\alpha+q_{i}-x_{i}-\gamma_{1} x_{j}\right) x_{i}-\left(\frac{q_{i}^{2}}{2}+\frac{x_{i}^{2}}{2}+q_{i} x_{i}\right)\right] \\
& +\delta\left(q_{i}\right)\left\{\left(1-\frac{c}{c}\right)\left[\left(\alpha+q_{i}-x_{i}-\gamma_{1} x_{j}\right) x_{i}-\left(\frac{q_{i}^{2}}{2}+\frac{x_{i}^{2}}{2}+q_{i} x_{i}\right)\right]-\frac{c}{c} \beta\right\}
\end{aligned}
$$

When the equilibrium product quality of enterprise $i$ and enterprise $j$ meet,

$$
\begin{aligned}
& q_{i}^{E Q}=\frac{9 \alpha\left(18+\gamma_{1}^{2} \gamma_{2}-3 \gamma_{1} \gamma_{2}-9 \gamma_{1}\right)}{324-189 \gamma_{1} \gamma_{2}+27 \gamma_{1}^{2} \gamma_{2}^{2}-\gamma_{1}^{3} \gamma_{2}^{3}} \geq \underline{q} \\
& q_{j}^{E Q}=\frac{9 \alpha\left(18+\gamma_{1} \gamma_{2}^{2}-3 \gamma_{1} \gamma_{2}-9 \gamma_{2}\right)}{324-189 \gamma_{1} \gamma_{2}+27 \gamma_{1}^{2} \gamma_{2}^{2}-\gamma_{1}^{3} \gamma_{2}^{3}} \geq \underline{q}
\end{aligned}
$$


At this moment, the equilibrium product qualities of both enterprises under double oligopolistic competition meet the lowest quality requirements. For the government, no supervision is needed for enterprises in double oligopolistic competition, and thus the optimal government supervision input is $c^{*}=0$.

When the equilibrium product qualities of enterprises $i$ and $j$ meet,

$$
\begin{gathered}
q_{i}^{E Q}=\frac{9 \alpha\left(18+\gamma_{1}^{2} \gamma_{2}-3 \gamma_{1} \gamma_{2}-9 \gamma_{1}\right)}{324-189 \gamma_{1} \gamma_{2}+27 \gamma_{1}^{2} \gamma_{2}^{2}-\gamma_{1}^{3} \gamma_{2}^{3}} \geq \underline{q} \\
q_{j}^{E Q}=\frac{9 \alpha\left(18+\gamma_{1} \gamma_{2}^{2}-3 \gamma_{1} \gamma_{2}-9 \gamma_{2}\right)}{324-189 \gamma_{1} \gamma_{2}+27 \gamma_{1}^{2} \gamma_{2}^{2}-\gamma_{1}^{3} \gamma_{2}^{3}}<\underline{q}
\end{gathered}
$$

The equilibrium product qualities of enterprises $i$ and $j$ are

$$
\begin{gathered}
q_{i}^{E Q^{*}}=\frac{9\left(\alpha \gamma_{1}+q \gamma_{1}-3 \alpha\right)}{\gamma_{1}^{2} \gamma_{2}^{2}-18 \gamma_{1} \gamma_{2}+54} \\
q_{j}^{E Q^{*}}=\underline{q}
\end{gathered}
$$

Under this circumstance, enterprise $j$ increases product quality to make the equilibrium quality of enterprise $i$ lower than the minimum quality requirements. Enterprise $i$ also faces the options of equilibrium quality and lowest quality. Therefore, when the product quality of enterprise $j$ is lower than the lowest quality standards or product quality of two enterprises that cannot meet the lowest quality standards, the double oligopolistic competition model is

$$
\begin{gathered}
\max _{x_{i}, q_{i}} \pi_{i}=\left(\alpha+q_{i}-x_{i}-\gamma_{1} x_{j}\right) x_{i}-\left(\frac{q_{i}^{2}}{2}+\frac{x_{i}^{2}}{2}+q_{i} x_{i}\right) \\
\max _{x_{j}, q_{j}} \pi_{j}=\left(\alpha+q_{j}-x_{j}-\gamma_{2} x_{i}\right) x_{j}-\left(\frac{q_{j}^{2}}{2}+\frac{x_{j}^{2}}{2}+q_{j} x_{j}\right) \\
\text { S.T. } q_{i}, q_{j} \geq \underline{q}
\end{gathered}
$$

\section{Analysis of results}

\subsection{Cournot competition model analysis under no resource constraint}

According to the first-order conditions, the equilibrium product qualities of enterprises $i$ and $j$ in a Cournot competition when there is no resource constraint are

$$
\begin{aligned}
& q_{i}^{E Q}=\frac{9 \alpha\left(18+\gamma_{1}^{2} \gamma_{2}-3 \gamma_{1} \gamma_{2}-9 \gamma_{1}\right)}{324-189 \gamma_{1} \gamma_{2}+27 \gamma_{1}^{2} \gamma_{2}^{2}-\gamma_{1}^{3} \gamma_{2}^{3}} \\
& q_{j}^{E Q}=\frac{9 \alpha\left(18+\gamma_{1} \gamma_{2}^{2}-3 \gamma_{1} \gamma_{2}-9 \gamma_{2}\right)}{324-189 \gamma_{1} \gamma_{2}+27 \gamma_{1}^{2} \gamma_{2}^{2}-\gamma_{1}^{3} \gamma_{2}^{3}}
\end{aligned}
$$


At this moment, the equilibrium product yields of enterprises $i$ and $j$ are

$$
\begin{aligned}
& x_{i}^{E Q}=\frac{\left(9-\gamma_{1} \gamma_{2}\right) \alpha\left(18+\gamma_{1}^{2} \gamma_{2}-3 \gamma_{1} \gamma_{2}-9 \gamma_{1}\right)}{324-189 \gamma_{1} \gamma_{2}+27 \gamma_{1}^{2} \gamma_{2}^{2}-\gamma_{1}^{3} \gamma_{2}^{3}} \\
& x_{j}^{E Q}=\frac{\left(9-\gamma_{1} \gamma_{2}\right) \alpha\left(18+\gamma_{1} \gamma_{2}^{2}-3 \gamma_{1} \gamma_{2}-9 \gamma_{2}\right)}{324-189 \gamma_{1} \gamma_{2}+27 \gamma_{1}^{2} \gamma_{2}^{2}-\gamma_{1}^{3} \gamma_{2}^{3}}
\end{aligned}
$$

Hence, the equilibrium earnings of enterprises $i$ and $j$ are as follows:

$$
\begin{aligned}
& \pi_{i}^{E Q}=\frac{3\left(\gamma_{1}^{2} \gamma_{2}^{2}-18 \gamma_{1} \gamma_{2}+54\right) \alpha^{2}\left(18+\gamma_{1}^{2} \gamma_{2}-3 \gamma_{1} \gamma_{2}-9 \gamma_{1}\right)^{2}}{2\left(324-189 \gamma_{1} \gamma_{2}+27 \gamma_{1}^{2} \gamma_{2}^{2}-\gamma_{1}^{3} \gamma_{2}^{3}\right)^{2}} \\
& \pi_{j}^{E Q}=\frac{3\left(\gamma_{1}^{2} \gamma_{2}^{2}-18 \gamma_{1} \gamma_{2}+54\right) \alpha^{2}\left(18+\gamma_{1} \gamma_{2}^{2}-3 \gamma_{1} \gamma_{2}-9 \gamma_{2}\right)^{2}}{2\left(324-189 \gamma_{1} \gamma_{2}+27 \gamma_{1}^{2} \gamma_{2}^{2}-\gamma_{1}^{3} \gamma_{2}^{3}\right)^{2}}
\end{aligned}
$$

Proposition 1: Under the oligopolistic competition, the advantageous party generates more high-quality products and gains higher profits. In other words, there are $q_{i}^{E Q}>q_{j}^{E Q}$, $x_{i}^{E Q}>x_{j}^{E Q}$, and $\pi_{i}^{E Q}>\pi_{j}^{E Q}$.

Proposition 1 shows equilibrium quality, yield, and profit under the double oligopolistic competition. The enterprise with stronger product substitutability has higher product yield and quality compared to the enterprise with weaker product substitutability. The stronger product substitutability propels the enterprise to occupy market shares of the competitor by increasing product yield and forcing the competitor to lower product yield. Meanwhile, it offsets profit loss caused by increasing yield as a result of the price drop by improving product quality.

\subsection{Cournot competition model analysis under yield resource constraint}

According to the first-order condition, the equilibrium product qualities of enterprises $i$ and $j$ in a Cournot competition when there are yield resource constraints are

$$
\begin{gathered}
q_{i}^{*}=\frac{\left(2 \gamma_{2} R-\alpha \theta-6 R\right) \gamma_{1}^{2}+\left[2 \gamma_{1}^{2} R-(2 \alpha \theta+19 R) \gamma_{1}+11 \alpha \theta+36 R\right] \gamma_{2}+\left(3-\gamma_{2}\right)\left[(\alpha \theta+3 R) \gamma_{2}-8 \alpha \theta-12 R\right]}{\theta\left(\gamma_{1}+\gamma_{2}-5\right)\left(\gamma_{1}+\gamma_{2}-8\right)\left(\gamma_{1}+\gamma_{2}-3\right)} \\
q_{j}^{*}=\frac{\left(2 \gamma_{1} R-\alpha \theta-6 R\right) \gamma_{2}^{2}+\left[2 \gamma_{2}^{2} R-(2 \alpha \theta+19 R) \gamma_{2}+11 \alpha \theta+36 R\right] \gamma_{1}+\left(3-\gamma_{1}\right)\left[(\alpha \theta+3 R) \gamma_{1}-8 \alpha \theta-12 R\right]}{\theta\left(\gamma_{1}+\gamma_{2}-5\right)\left(\gamma_{1}+\gamma_{2}-8\right)\left(\gamma_{1}+\gamma_{2}-3\right)}
\end{gathered}
$$

In this case, the equilibrium product yields of enterprises $i$ and $j$ are

$$
\begin{aligned}
& x_{i}^{*}=\frac{R\left[\gamma_{1}^{2}+\left(\gamma_{2}-8\right) \gamma_{1}-3 \gamma_{2}+12\right]}{\theta\left(\gamma_{1}+\gamma_{2}-8\right)\left(\gamma_{1}+\gamma_{2}-3\right)} \\
& x_{j}^{*}=\frac{R\left[\gamma_{2}^{2}+\left(\gamma_{1}-8\right) \gamma_{2}-3 \gamma_{1}+12\right]}{\theta\left(\gamma_{1}+\gamma_{2}-8\right)\left(\gamma_{1}+\gamma_{2}-3\right)}
\end{aligned}
$$


Hence, the equilibrium earnings of enterprises $i$ and $j$ are

$$
\begin{aligned}
& \pi_{i}^{*}=\left(\alpha+q_{i}^{*}-x_{i}^{*}-\gamma_{1} x_{j}^{*}\right) x_{i}^{*}-\left(\frac{q_{i}^{* 2}}{2}+\frac{x_{i}^{* 2}}{2}+q_{i}^{*} x_{i}^{*}\right) \\
& \pi_{j}^{*}=\left(\alpha+q_{j}^{*}-x_{j}^{*}-\gamma_{2} x_{i}^{*}\right) x_{j}^{*}-\left(\frac{q_{j}^{* 2}}{2}+\frac{x_{j}^{* 2}}{2}+q_{j}^{*} x_{j}^{*}\right)
\end{aligned}
$$

Proposition 2: Under the oligopolistic competition, the advantageous party generates more high-quality products when there is a production capacity constraint. In other words, $q_{i}^{*}>q_{j}^{*}$ and $x_{i}^{*}>x_{j}^{*}$. In this case, the resource constraint is a tight constraint, which means $x_{i}^{*}+x_{j}^{*}=\frac{R}{\theta}$.

Proposition 2 shows the equilibrium quality, yield, and profits under a yield capacity constraint. Similar with Proposition 1, the enterprise with stronger product substitutability has higher product yield and quality compared to the enterprise with weaker product substitutability. In this case, the yield competition urges competing enterprises to make full use of available yield resources under the Cournot competition.

Figure no. 1 shows that with the increase of $\gamma_{1}$, the profits of enterprise $i$ decrease gradually while the profits of enterprise $j$ increase gradually, thus narrowing the profit difference between the two enterprises. This outcome indicates that when the products of enterprise $i$ have stronger substitutability than those of enterprise $j$, the former can occupy the market shares of the latter by increasing the yield and quality of its products, thus enabling it to gain higher earnings.

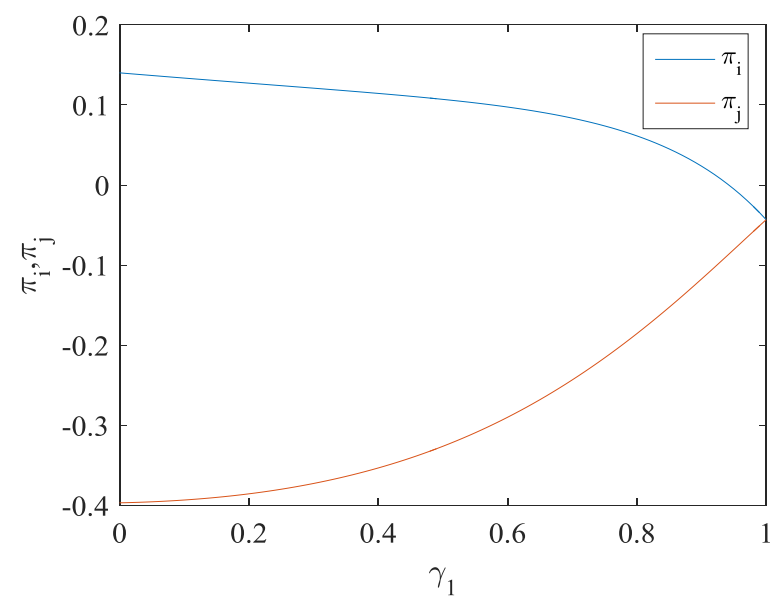

Figure no. 1: Enterprise profit curve in double oligopolistic competition under yield resource constraint ( $\alpha=1, \gamma_{2}=1, \theta=1.5$, and $R=1$ ) 


\subsection{Cournot competition model analysis under quality resources constraint}

According to the first-order condition, the equilibrium product qualities of enterprises $i$ and $j$ in a Cournot competition when there is a quality capacity constraint are as follows:

$$
\begin{aligned}
& q_{i}^{* *}=\frac{R \gamma_{1}^{2} \gamma_{2}^{2}-9 \alpha \theta \gamma_{1}+9 \alpha \theta \gamma_{2}-18 \gamma_{1} \gamma_{2} R-9 \gamma_{1} R+54 R}{\theta\left(2 \gamma_{1}^{2} \gamma_{2}^{2}-36 \gamma_{1} \gamma_{2}-9 \gamma_{1}-9 \gamma_{2}+108\right)} \\
& q_{j}^{* *}=\frac{R \gamma_{1}^{2} \gamma_{2}^{2}+9 \alpha \theta \gamma_{1}-9 \alpha \theta \gamma_{2}-18 \gamma_{1} \gamma_{2} R-9 \gamma_{2} R+54 R}{\theta\left(2 \gamma_{1}^{2} \gamma_{2}^{2}-36 \gamma_{1} \gamma_{2}-9 \gamma_{1}-9 \gamma_{2}+108\right)}
\end{aligned}
$$

At this moment, the equilibrium product yields of enterprises $i$ and $j$ are

$$
\begin{aligned}
& x_{i}^{* *}=\frac{(2 \alpha \theta+R)\left(\gamma_{1}^{2} \gamma_{2}-3 \gamma_{1} \gamma_{2}-9 \gamma_{1}+18\right)}{\theta\left(2 \gamma_{1}^{2} \gamma_{2}^{2}-36 \gamma_{1} \gamma_{2}-9 \gamma_{1}-9 \gamma_{2}+108\right)} \\
& x_{j}^{* *}=\frac{(2 \alpha \theta+R)\left(\gamma_{1} \gamma_{2}^{2}-3 \gamma_{1} \gamma_{2}-9 \gamma_{2}+18\right)}{\theta\left(2 \gamma_{1}^{2} \gamma_{2}^{2}-36 \gamma_{1} \gamma_{2}-9 \gamma_{1}-9 \gamma_{2}+108\right)}
\end{aligned}
$$

Therefore, the equilibrium earnings of enterprises $i$ and $j$ are

$$
\begin{aligned}
& \pi_{i}^{* * *}=\left(\alpha+q_{i}^{* *}-x_{i}^{* *}-\gamma_{1} x_{j}^{* *}\right) x_{i}^{* *}-\left(\frac{q_{i}^{* * 2}}{2}+\frac{x_{i}^{* * 2}}{2}+q_{i}^{* * *} x_{i}^{* *}\right) \\
& \pi_{j}^{* *}=\left(\alpha+q_{j}^{* *}-x_{j}^{* *}-\gamma_{2} x_{i}^{* *}\right) x_{j}^{* *}-\left(\frac{q_{j}^{* * 2}}{2}+\frac{x_{j}^{* * 2}}{2}+q_{j}^{* *} x_{j}^{* *}\right)
\end{aligned}
$$

Proposition 3: Under oligopolistic competition, the advantageous party will produce more high-quality products when there is a quality capacity constraint: $q_{i}^{* *}>q_{j}^{* *}$ and $x_{i}^{* *}>x_{j}^{* *}$. At this moment, the resource constraint is a tight constraint and $q_{i}^{* *}+q_{j}^{* *}=\frac{R}{\theta}$.

Proposition 3 shows the equilibrium quality, yield, and profits when there is a quality capacity constraint. Similar with Propositions 1 and 2, the enterprise with stronger product substitutability has higher product yield and quality compared to the enterprise with weaker product substitutability. On the one hand, strong product substitutability drives the enterprise to use its substitutability advantages to expand yield. On the other hand, the price drop caused by increasing yield is offset by increasing product quality. Nevertheless, the enterprise with stronger product substitutability may not always gain higher profits due to the quality resource constraint. In this case, the relationship between the two enterprises in terms of earnings has the following three situations.

Figure no. 2 reveals that the profits of enterprise $i$ are always lower than those of enterprise $j$, and the profit difference between the two enterprises increases initially and then decreases with the increase of $\gamma_{1}$. Both enterprises are in the deficit state. Owing to differences in product substitutability, enterprise $i$ will increase its yield and quality. The enterprise with stronger product substitutability suffers more losses as a result of the production resource constraint over product quality. The profit difference between the two enterprises is relatively small when $\gamma_{1}$ is very large or very small. 


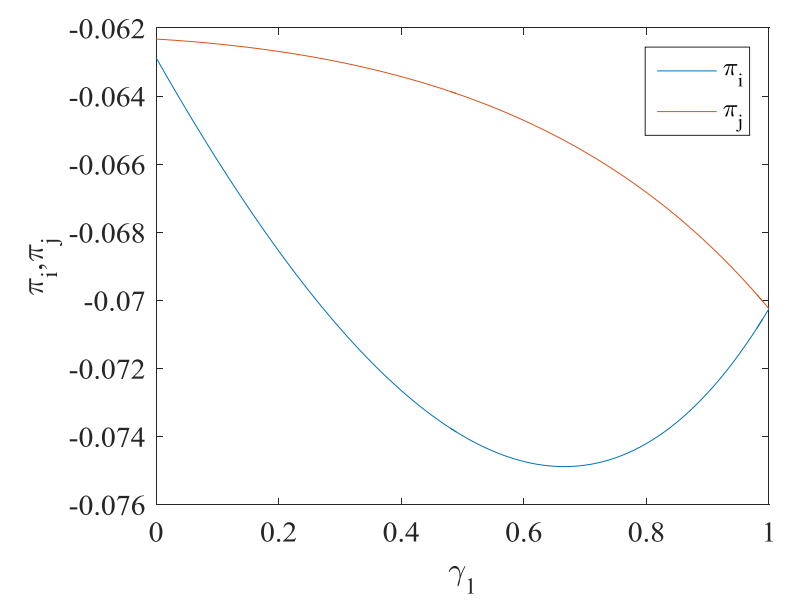

Figure no. 2: Enterprise profit curve in double oligopolistic competition under quality resource constraint $\left(\alpha=1, \gamma_{2}=1, \theta=1.1\right.$, and $\left.R=1\right)$

Figure no. 3 shows that the profit of enterprise $i$ is higher than that of enterprise $j$ when $\gamma_{1}$ is relatively small. With the increase of $\gamma_{1}$, the profit of enterprise $j$ is higher compared to that of enterprise $i$. The profit of enterprise $i$ presents a $\mathrm{V}$-shaped variation with the increase of $\gamma_{1}$. The profit of enterprise $j$ is negatively related with $\gamma_{1}$. Both enterprises are in deficit states. With the increase $\theta$, production resources have stronger constraint over product quality and restrict enterprise $j$, which has weaker product substitutability, to offset early substitutability-induced loss by increasing product quality. This condition brings higher profits to enterprise $i$, which has stronger product substitutability, by increasing the yield. As $\gamma_{1}$ increases, the substitutability advantages of enterprise $i$ are weakened. Therefore, enterprise $j$ can gain relatively higher profits even though enterprise $i$ has higher yield and quality.

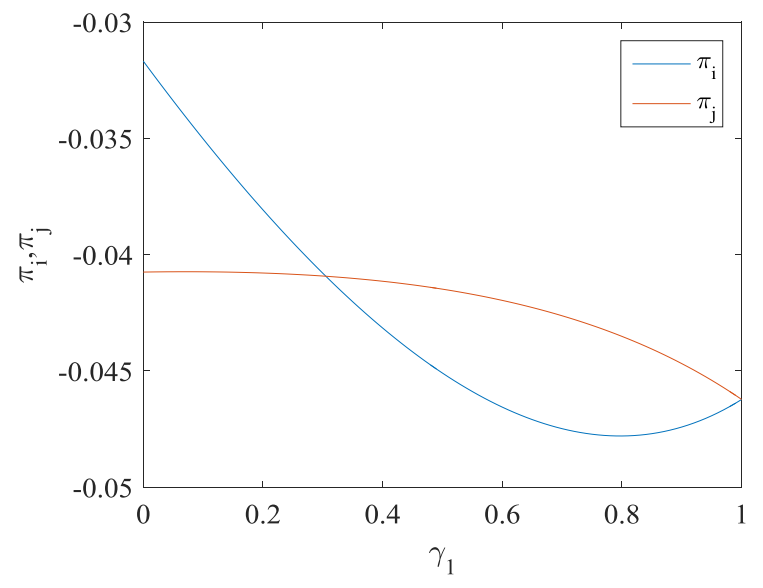

Figure no. 3: Enterprise profit curve in double oligopolistic competition under quality resource constraint $\left(\alpha=1, \gamma_{2}=1, \theta=1.2\right.$, and $R=1$ ) 
Figure no. 4 shows that the profits of enterprise $i$ are always higher than those of enterprise $j$. With the increase of $\gamma_{1}$, the profit of enterprise $i$ decreases, while the profit of enterprise $j$ increases gradually, thus gradually narrowing the profit difference between the two enterprises. This outcome reflects that when $\theta$ is relatively high, production resource has a very strong constraint over product quality and restricts enterprise $j$, which has weaker substitutability, from offsetting loss caused by substitutability by improving product quality. On the contrary, enterprise $i$ can easily gain higher benefits by increasing product yield.

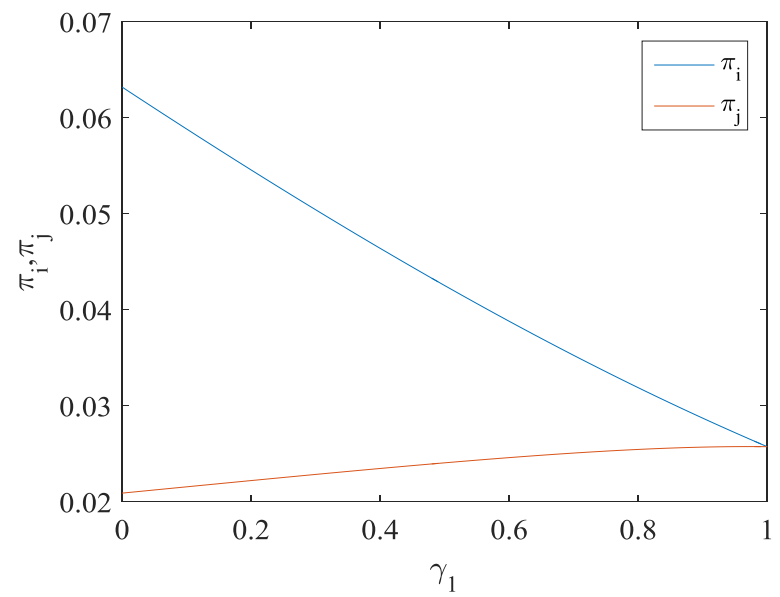

Figure no. 4: Enterprise profit curve in double oligopolistic competition under quality resource constraint $\left(\alpha=1, \gamma_{2}=1, \theta=1.8\right.$, and $\left.R=1\right)$

3.4. Enterprise quality decision analysis under government supervision and optimal government supervision input

Given government supervision, the equilibrium product qualities of enterprises $i$ and $j$ in

Cournot competition are

$$
q_{i}^{E Q^{*}}=q_{j}^{E Q^{*}}=\underline{q}
$$

Equilibrium yields of enterprises $i$ and $j$ are

$$
\begin{aligned}
x_{i}^{E Q^{*}} & =\frac{3 \underline{q}+3 \alpha-\alpha \gamma_{1}-\gamma_{1} \underline{q}}{9-\gamma_{1} \gamma_{2}} \\
x_{j}^{E Q^{*}} & =\frac{3 \underline{q}+3 \alpha-\alpha \gamma_{2}-\gamma_{2} \underline{q}}{9-\gamma_{1} \gamma_{2}}
\end{aligned}
$$


Equilibrium profits of enterprises $i$ and $j$ are

$$
\begin{aligned}
& \pi_{i}^{E Q^{*}}=\frac{\left[\left(3-\gamma_{1}^{2}\right) \underline{q}^{2}+6 \alpha \underline{q}+3 \alpha^{2}\right] \gamma_{2}^{2}+\left[\left(18 \gamma_{1}-18\right) \underline{q}^{2}-36 \alpha \underline{q}-18 \alpha^{2}\right] \gamma_{2}+27 \alpha^{2}+54 \alpha \underline{q}-54 \underline{q}^{2}}{2\left(9-\gamma_{1} \gamma_{2}\right)^{2}} \\
& \pi_{j}^{E Q^{*}}=\frac{\left[\left(3-\gamma_{2}^{2}\right) \underline{q}^{2}+6 \alpha \underline{q}+3 \alpha^{2}\right] \gamma_{1}^{2}+\left[\left(18 \gamma_{2}-18\right) \underline{q}^{2}-36 \alpha \underline{q}-18 \alpha^{2}\right] \gamma_{1}+27 \alpha^{2}+54 \alpha \underline{q}-54 \underline{q}^{2}}{2\left(9-\gamma_{1} \gamma_{2}\right)^{2}}
\end{aligned}
$$

Proposition 4: Given government supervision, both enterprises $i$ and $j$ produce products according to the lowest quality requirements: $q_{i}^{E Q^{*}}=q_{j}^{E Q^{*}}=\underline{q}$. The advantageous party will produce more products: $x_{i}^{E Q^{*}}>x_{j}^{E Q^{*}}$. In this case, the advantageous party possesses lower profits: $\pi_{i}^{E Q^{*}}<\pi_{j}^{E Q^{*}}$.

Proposition 4 shows the equilibrium quality, yield, and profit under government supervision. At this circumstance, both enterprises produce products according to the lowest quality requirements of the government to avoid relevant penalty risks. The enterprise with stronger product substitutability has higher product yield but lower profits compared to the enterprise with weak product substitutability. This result demonstrates that government supervision forces both enterprises to improve product quality, which incurs higher quality costs. This adverse factor influences the enterprise with stronger product substitutability more, so the enterprise encounters difficulty in gaining advantages through yield competition.

Meanwhile, it can be known from $\pi_{i}^{E Q}>\pi_{j}^{E Q}$ that

$$
\begin{aligned}
& \left(1-\frac{c}{c}\right) \pi_{i}^{E Q}-\frac{c}{c} \beta>\pi_{i}^{E Q^{*}} \\
& \left(1-\frac{c}{\bar{c}}\right) \pi_{j}^{E Q}-\frac{c}{c} \beta>\pi_{j}^{E Q^{*}}
\end{aligned}
$$

Whether enterprises $i$ and $j$ are intended to improve product quality is determined by enterprise $j$. When $\frac{c}{c}<\frac{\pi_{j}^{E Q}-\pi_{j}^{E Q^{*}}}{\pi_{j}^{E Q}+\beta}$, the enterprise takes certain risks to produce low-quality products. When $\underset{c}{\bar{c}} \geq \frac{\pi_{j}^{E Q}-\pi_{j}^{E Q^{*}}}{\pi_{j}^{E Q}+\beta}$, enterprises produce products according to the lowest quality standards.

For the government,

$$
\max _{c} \pi_{G}=\frac{c}{c}\left(\pi_{j}^{E Q}+\beta\right)-\frac{c^{2}}{2}
$$

The optimal supervision input is

$$
c^{*}=\frac{\pi_{j}^{E Q}+\beta}{\bar{c}}
$$


Therefore, enterprises will take certain risks to produce low-quality products when $\left(\pi_{j}^{E Q}+\beta\right)^{2}<c^{-2}\left(\pi_{j}^{E Q}-\pi_{j}^{E Q^{*}}\right)$, and they will produce products according to the lowest quality standards when $\left(\pi_{j}^{E Q}+\beta\right)^{2}>c^{-2}\left(\pi_{j}^{E Q}-\pi_{j}^{E Q^{*}}\right)$. Obviously, the higher value of $\beta$ is beneficial for enterprises to produce products according to quality standards. On the contrary, the higher value of $\bar{c}$ will make enterprises take certain risks to produce low-quality products. When the product quality of an enterprise is lower than the lowest quality standards, the government imposes a high penalty to the enterprise for disqualified products to force it to improve product quality. Under this circumstance, the enterprise will produce products according to the lowest quality standards to avoid the penalty from the government. When there is great difficulty for government supervision, the enterprise decides to gain higher benefits with disqualified products.

\section{Discussions}

Consumers are apt to buy products manufactured by enterprises with great brand influence. Nevertheless, food quality safety accidents in leading food production enterprises have been exposed frequently in recent years, causing a crisis of consumer trust in them. Consumers do not choose products of large enterprises blindly. On the basis of the Cournot competition, this study investigated the influences of product substitutability differences of enterprises on their yield and quality decisions and interpreted the causes of quality safety accidents in large enterprises. Different from previous studies (Migliore et al., 2015), enterprises in double oligopolistic competition do not adopt the same yield and quality decisions when they have different product substitutability. The enterprise with stronger product substitutability will increase product yield and quality to occupy the market shares of the enterprise with weaker product substitutability and gain higher profits. Hence, government should strengthen quality supervision over small-sized enterprises with weak product substitutability to assure their products meet quality standards.

However, large enterprises have to choose either product quality or profits when smallsized enterprises choose to produce low-quality products. At this moment, large enterprises may produce low-quality products to gain high profits under government supervision. When the government faces great challenges in supervision or imposes a light penalty, these enterprises are more likely to have quality accidents. Under this circumstance, the government lowers the product quality safety risk of enterprises and propels enterprises to produce products according to the lowest quality standards by increasing supervision input or formulating stricter penalty measures. The four propositions give some enlightenment.

First, Propositions 1-3 demonstrate that to occupy the market, food enterprise with stronger product substitutability has a stronger motivation to improve quality. In the situation without food safety regulation policies, the product substitutability of food enterprises is generally proportional to quality. In other words, the stronger the product substitutability, the higher the product quality, whereas the weaker the product substitutability, the lower the product quality. As a result, enterprises with strong product differences more easily damage consumer welfare through quality standards (Garella and Petrakis, 2008). When the implementation of government regulations on food safety has some resource constraints, the government can observe the law and use product substitutability as an index to allocate resources for implementing food safety regulations and maximize the implementation 
effect. To pursue the maximum effect of food safety regulations, weaker product substitutability requires more resources to implement food safety regulations.

Second, Proposition 4 reflects that to realize the lowest quality requirements regulated by the government, food enterprises with strong product substitutability will produce more products but gain lower profits. Meanwhile, food enterprises with weak product substitutability will produce fewer products but gain more profits. Therefore, product substitutability determines the profits of food enterprises with different product substitutability when they observe the same lowest quality standards. The enterprise with stronger product substitutability has lower profits. In the long run, capitals tend to be input into high-profit fields, indicating that enterprises with weaker product substitutability will expel enterprises with stronger product substitutability and influence the supply of the whole food market, finally influencing the overall social welfare. This finding reveals that when the government formulates food safety regulation policies, it should pay attention to the following two aspects. On the one hand, the influences of product substitutability on food enterprises should be considered. On the other hand, the market distortion effect wherein capitals prefer food enterprises with weaker product substitutability in the long run because the same quality standards are observed should be taken into account (Marette, 2007).

Third, on the other hand, according to the conclusion of the theoretical model, in order to improve the quality of products without damaging the profits of enterprises, the government can set higher quality standards for products with strong substitutability, and the government can formulate qualified quality standards for products with low substitutability, but at the same time strengthen supervision and inspection. Enterprises with strong product substitutability have greater market competition pressure, more intense quality competition, and sufficient number of production enterprises. Improving product quality standards can help to eliminate enterprises with ordinary product quality, and ensure that enterprises can increase enterprise profits. Enterprises with weak product substitutability have low market competition pressure, low quality competition intensity, and insufficient number of production enterprises. Setting up qualified but not high standard product quality standards helps to ensure the number of enterprises. Under the condition of strengthening supervision and inspection, ensuring the quality of enterprise products and ensuring sufficient output can improve the profits of enterprises.

\section{Conclusions}

This study investigated the yield and quality decisions of food enterprises under no resource constraint and under yield and quality resource constructs. Equilibrium yield and quality of enterprises are analyzed by establishing Cournot models. The conclusions could be drawn: (1) Under all conditions, enterprises with stronger product substitutability own higher yield and ensure higher quality of food products than do enterprises with weaker food product's substitutability. (2) When there is no quality resource constraint but there is yield resource constraint, enterprises with stronger product substitutability gain higher profits. (3) In the situation of quality resource constraint, enterprises with stronger product substitutability have lower profit than do enterprises with weaker product substitutability. (4) Given government supervision, enterprises are urged to improve product quality due to the high penalty or lower government supervision difficulty when the equilibrium quality of an enterprise is lower than the lowest quality standards set by the government. At this 
moment, both enterprises produce products according to the lowest quality standards. (5) On the contrary, low penalty or great government supervision difficulty forces enterprises to take certain risks to produce low-quality products and gain higher profits.

The main policy implications of conducted study is to improve governance of food quality undertaken by the government in order to avoid situation that companies try to increase profits by lowering food production quality. State policies for securing food quality should ensure that under government supervision, enterprises are urged to improve product quality due to the high penalty or lower government supervision difficulty when the equilibrium quality of an enterprise is lower than the lowest quality standards set by the government. However, under government supervision, the punishment imposed by government will increase expenditures and lower the profits of food enterprises. Government can reward or subsidize food enterprises which comply with the food quality regulation. Compared with punishment, the reward or subsidy will encourage enterprises to produce qualified food products without damage to the profit of enterprises, although it will also raise government expenditures. Therefore, government should pay attention to the food enterprises with higher product substitutability and reward or subsidize them, which will protect them from the damage of unqualified food products with weaker product substitutability.

This study investigates the equilibrium yield and quality of food products for enterprises under a Cournot competition. However, some aspects still require further explorations. On the one hand, different positions of enterprises on the market are ignored. The advantageous party often occupies the dominant role on the market and becomes the pioneer of the Steinberg game. On the other hand, this study considers the substitutability of product yield to other products but ignores the impacts of product quality on product substitutability. These limitations of current research are necessary to address in future research.

\section{Acknowledgement}

This study was funded by the National Social Science Foundation of China (grant number 15ZDB168). We thank D. Fang, W. Lyu and M. Li for their advice.

\section{References}

Aray, Y., Veselova, A., Knatko, D. and Levchenko, A., 2020. Drivers for adoption of sustainability initiatives in supply chains of large Russian firms under environmental uncertainty. Corporate Governance: The International Journal of Business in Society. Ahead-of-print. https://doi.org/10.1108/CG-02-2020-0048.

Besanko, D, Dubé, J. and Gupta, S., 2005. Own-brand and cross-brand retail pass-through. Marketing Science, 24(1), pp.123-137.

Bojanić, B., 2015. Analysis of supervision of the quality management system from the highest management of an organization. Tehnicki Glasnik-Technical Journal, 9(3), pp.321-326.

Chen, C., Zhang, J. and Delaurentis, T., 2014. Quality control in food supply chain management: An analytical model and case study of the adulterated milk incident in China. International Journal of Production Economics, [e-journal] 152, pp.188-199. DOI: 10.1016/j.ijpe.2013.12.016. 
Chen, Y. and Nie, P., 2014. Duopoly innovation under product externalities. Economic Research-Ekonomska Istrazivanja, 27(1), pp.232-243.

Chen, Y., Huang, S., Mishra, A. K. and Wang, X. H., 2018. Effects of input capacity constraints on food quality and regulation mechanism design for food safety management. Ecological Modelling, [e-journal] 385(C), pp.89-95. DOI: 10.1016/j.ecolmodel.2018.03.011.

Chen, Y., Nie, P. and Yang, Y., 2017. Effects of corporate social responsibility on food safety. Agricultural Economics-Zemedelska Ekonomika, 63(12), pp.539-547.

Civera, C., De Colle, S. and Casalegno, C., 2019. Stakeholder engagement through empowerment: The case of coffee farmers. Business Ethics: A European Review, 28(2), pp.156-174.

Cunha, M. and Mota, F., 2020. Coordinated effects of corporate social responsibility. Journal of Industry, Competition and Trade, [e-journal] 20, pp.617-641. DOI: $10.1007 / \mathrm{s} 10842-020-00344-2$.

Datta, A. K., Ukidwe, M. S. and Way, D. G., 2020. Simulation- based enhancement of learning: the case of food safety. Journal of Food Science Education, 19(3), pp.192-211.

Garella, P. G. and Petrakis, E., 2008. Minimum quality standards and consumers' information. Economic Theory, 36(2), pp.283-302.

Han, F. and Li, H., 2017. Food safety evolutionary game simulation model based on improved prospect theory. Journal of Interdisciplinary Mathematics, [e-journal] 20(67), pp.1349-1354. https://doi.org/10.1080/09720502.2017.1384216

Hatami, A. and Firoozi, N., 2019. A dynamic stakeholder model: an other- oriented ethical approach. Business Ethics: A European Review, 28(3), pp.349-360.

Liu, P. and Ma, L., 2016. Food scandals, media exposure, and citizens' safety concerns: A multilevel analysis across Chinese cities. Food Policy, [e-journal] 63, pp.102-111. DOI: 10.1016/j.foodpol.2016.07.005

Liu, P., 2010. Tracing and periodizing China's food safety regulation: A study on China's food safety regime change. Regulation \& Governance, 4(2), pp.244-260.

Liu, R., Pieniak, Z. and Verbeke, W., 2013. Consumers' attitudes and behaviour towards safe food in China: a review. Food Control, 33(1), pp.93-104.

Lu, J. T., Ren, L. C., Yao, S. Q., Qiao, J. Y., Mikalauskiene, A. and Streimikis, J., 2020. Exploring the relationship between corporate social responsibility and firm competitiveness. Economic Research-Ekonomska Istraživanja, 33(1), pp.1621-1646.

Lu, J. T., Ren, L. C., Zhang, C., Liang, M. S., Abrham, J. and Streimikis, J., 2020. Assessment of Corporate Social Responsibility performance and state promotion policies: a case study of The Baltic States. Journal of Business Economics and Management, 21(4), pp.1203-1224.

Luo, J., Ma, B., Zhao, Y. and Chen, T., 2018. Evolution model of health food safety risk based on prospect theory. Journal of Healthcare Engineering, 2018, pp.1-12. DOI: $10.1155 / 2018 / 8769563$.

Luo, X., Han, Y., Chen, X., Tang, W., Yue, T. and Li, Z., 2020. Carbon dots derived fluorescent nanosensors as versatile tools for food quality and safety assessment: A review. Trends in Food Science and Technology, 95, pp.149-161.

Marette, S., 2007. Minimum safety standard, consumers' information and competition. 
Journal of Regulatory Economics, 32(3), pp.259-285.

Mauricio, A., Latapí, A, Lára J. and Brynhildur D., 2019. A literature review of the history and evolution of corporate social responsibility. International Journal of Corporate Social Responsibility, 4(1), pp.1-23.

Migliore, G., Schifani, G. and Cembalo, L., 2015. Opening the black box of food quality in the short supply chain: Effects of conventions of quality on consumer choice. Food Quality and Preference, [e-journal] 39, pp.141-146. DOI: 10.1016/j.foodqual. 2014.07.006.

Neumann-Langdon, P., Oviedo-Silva, C., Suazo-Schwencke, A., Ramis-Lanyon, F. and Delgado-Neira, P., 2019. Technological and management aspects of the anaerobic codigestion of sewage sludge with vegetable and organic wastes. Dyna, 94(5), pp.574-578.

Nguyen, M., Bensemann, J. and Kelly, S., 2018. Corporate social responsibility (CSR) in vietnam: a conceptual framework. International Journal of Corporate Social Responsibility, 3(1), pp.1-12.

Nie, P., 2014. Effects of capacity constraints on mixed duopoly. Journal of Economics, 112(3), pp.283-294.

Parker, J. S., DeNiro, J., Ivey, M. L. and Doohan, D., 2016. Are small and medium scale produce farms inherent food safety risks? Journal of Rural Studies, [e-journal] 44, pp.250-260. DOI: 10.1016/j.jrurstud.2016.02.005.

Pei, X., Tandon, A., Alldrick, A., Giorgi, L., Huang, W. and Yang, R., 2011. The China melamine milk scandal and its implications for food safety regulation. Food Policy, 36(3), pp.412-420.

Peng, Y., Li, J., Xia, H., Qi, S. and Li, J., 2015. The effects of food safety issues released by we media on consumers' awareness and purchasing behavior: A case study in China. Food Policy, [e-journal] 51(C), pp.44-52. DOI: 10.1016/j.foodpol.2014.12.010.

Petrovic, D., Jurisic, M., Tadic, V., Plascak, I. and Barac, Z., 2018. Different sensor systems for the application of variable rate technology in permanent crops. Tehnicki Glasnik-Technical Journal, 12(3), pp.188-195.

Pineda-Escobar, M. A., 2019. Moving the 2030 agenda forward: SDG implementation in Colombia. Corporate Governance: The International Journal of Business in Society, 19 (1), pp.176-188.

Pinstrup-Andersen, P., 2009. Food security: definition and measurement. Food Security, 1(1), pp.5-7.

Rodriguez-Parada, L., Pardo-Vicente, M. A. and Mayuet-Ares, P. F., 2018. Digitalization fresh food using 3D scanning for custom packaging design. Dyna, 93(6), pp.681-688.

Rong, A., Akkerman, R. and Grunow, M., 2011. An optimization approach for managing fresh food quality throughout the supply chain. International Journal of Production Economics, 131(1), pp.421-429.

Rouvière, E., 2016. Small is beautiful: firm size, prevention and food safety. Food Policy, 63, pp.12-22.

Shaffer, G. and Zettelmeyer, F., 2004. Advertising in a distribution channel. Marketing Science, 23(4), pp.619-628.

Song, Y., Shen, N. and Liu, D., 2018. Evolutionary game and intelligent simulation of food safety information disclosure oriented to traceability system. Journal of Intelligent and 
Fuzzy Systems, 35(3), pp.2657-2665.

Tirado, M. C., Clarke, R., Jaykus, L. A., Mcquatters-gollop, A. and Frank, J. M., 2010. Climate change and food safety: A review. Food Research International, 43(7), pp.1745-1765.

Tomerlin, R., Tomisa, M. and Vusic, D., 2019. The influence of printing, lamination and high pressure processing on spot color characterization. Tehnicki Glasnik-Technical Journal, 13(3), pp.218-225.

Van Der Vorst, J. G., Tromp, S. O. and Van Der Zee, D. J., 2009. Simulation modelling for food supply chain redesign; integrated decision making on product quality, sustainability and logistics. International Journal of Production Research, 47(23), pp.6611-6631.

Vives, X., 2008. Innovation and competitive pressure. The Journal of Industrial Economics, 56(3), pp.419-469.

Wang, J., Chen, T. and Wang, J., 2015. Research on cooperation strategy of enterprises' quality and safety in food supply chain. Discrete Dynamics in Nature and Society, [ejournal] 2015. https://doi.org/10.1155/2015/301245

Wang, Z., Mao, Y. and Gale, F., 2008. Chinese consumer demand for food safety attributes in milk products. Food Policy, 33(1), pp.27-36.

Xu, J., Yao, G. and Dai, P., 2020. Quality decision-making behavior of bodies participating in the agri-Foods e-supply chain. Sustainability, 12(5), pp.1874.

Yan, Y., 2012. Food Safety and Social Risk in Contemporary China. The Journal of Asian Studies, 71(3), pp.705-729.

Yang, Y. and Nie, P., 2016. Asymmetric competition in food industry with product substitutability. Agricultural Economics-Zemedelska Ekonomika, 62(7), pp.324-333.

Zheng, Q., Pan, X. A. and Vakharia, A. J., 2020. Common retailer channel revisited: the role of supply network size. Production and Operations Management, 29(9), pp.2175-2181. 